\title{
FRONTEIRAS, TERRITÓRIOS E TERRITORIALIDADES ${ }^{1}$
}

\author{
Maria Geralda de Almeida \\ Professora da Universidade Federal de Goiás \\ galmeida@iesa.ufg.br
}

\section{Resumo}

O propósito deste artigo é discutir as noções de território de fronteira e territorialidades. Para isso, a construção do Lago da Usina Hidrelétrica (UHE) da Serra da Mesa, no Norte Goiano será utilizada. Fronteira, uma categoria ambígua e de pouca discussão na Geografia, terá o seu enfoque enquanto limite socioespacial, que separa e delimita realidades. Será discutido o empreendimento e os diversos entendimentos de território e de fronteira para, posteriormente, tratar-se de identidades e de alteridades e contextualizar os territórios identitários. Nas considerações finais serão apontadas algumas perspectivas para os territórios e as territorialidades face às novas dinâmicas sociais, na persistência e construção de identidades.

Palavras-chave: fronteira- território identitário -alteridadeUHE do Lago da Serra da Mesa.

\begin{abstract}
Abstratct
The goal of this paper is to extend the debate about the border territory from the analysis of "Serra da Mesa" Lake construction, in the north of Goiás state. Border is an ambiguous category and it has been little argued in Geography. In its study, border will be approached while social and spatial limit, that separates and delimits realities. The enterprise and the various agreements of territory and border will be discussed. Then, identities and alteridades (no-identities?) will be focused as well as the recognition of identities territories. Finally, some of perspectives for territories and territorialities will be pointed in relation to the new social dynamics in the persistence and construction of identities.
\end{abstract}

Key Words: Border - identity territory - no-identity - Serra da Mesa Lake (plant of hydro-electric energy production)

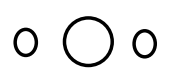

O desenvolvimento do capitalismo gerou, no Brasil, ao longo do tempo, desigualdades regionais. Algumas dessas desigualdades foram acentuadas devido à construção de grandes hidrelétricas as quais representam um formato particular de controle do território.Elas constituem empreendimentos que consolidam o processo de apropriação de recursos naturais e humanos em determinados pontos do território, sob lógica estritamente econômica, respondendo a decisões estabelecidas sob a égide do capital industrial-financeiro do Sudeste-Sul do país. Todavia, se a produção de energia atende aos interesses de territórios distantes do empreendimento, as hidrelétricas estão longe de serem neutras em relação ao espaço no qual se instalam.

Para a construção das hidrelétricas as periferias são, por excelência, diretamente investidas por um movimento de conquistas e tornam-se fronteiras de recursos nas quais os bens estratégicos, como a água, devem ser apropriados e explorados. Regiões inteiras, extensas bacias, ricas várzeas são cobiçadas para a produção de energia.

A construção das hidrelétricas forma enclaves modernos e os desdobramentos políticos dela decorrentes tendem a romper com as tramas e com os laços que conformam as relações de identidade com o território, alterando-as ou substituindo-as por outras. Este rompimento ocorre uma vez que os habitantes locais passam a se relacionar com outros territórios impostos no ato de construção de barragens e usinas hidrelétricas. As atividades econômicas, a vida social, as relações das populações que ai residem defrontam-se, portanto, com o novo, o ambiente desconhecido proposto pelo sistema hidrelétrico. 
Este espaço “de des-territorialização, de desraizamento das identidades territoriais está nas fronteiras”, conforme Haesbaert (2001, p.126). A fronteira é interpretada essencialmente como lugar de alteridade que, no Norte Goiano se configura com a construção da Usina Hidrelétrica da Serra da Mesa, a qual nos interessa. Por que a alteridade? Ora, de acordo com Martins (1997, p.150), a fronteira "a primeira vista é o lugar do encontro dos que por diferentes razões são diferentes entre si (...)a um só tempo é o lugar de descoberta do outro, e de desencontro.O desencontro e o conflito decorrentes das diferentes concepções de vida e visões de mundo de cada um (...). O desencontro nas fronteiras é o desencontro de temporalidades históricas.”A fronteira está, portanto, nos homens.

Diante de tudo isso,o propósito deste artigo é ampliar o foco sobre o território de fronteira. Para isso, o Lago da UHE da Serra da Mesa, será utilizado como via possibilitadora de compreensão de fronteira, uma categoria ambígua e de pouca discussão na Geografia. Como qualquer outro limite social, a fronteira separa e delimita nossa realidade de outras realidades. Neste sentido, podemos interpretar que, para as populações do Norte Goiano, a construção do Lago constituiu o contato com outras realidades, a aproximação de um mundo até então desconhecido, ausente de suas referências espaciais e culturais. Foi, portanto, a inserção de tais populações no conflito mencionado por Martins (1997), o qual configurou a fronteira como lugar, motivo desta reflexão.

Abordaremos, inicialmente, as diversas concepções de território e de fronteira para, posteriormente, tratarmos de identidades e de alteridades e contextualizarmos os territórios identitários. Estes, aqui, serão ilustrados com aqueles sócio-territoriais identificados e existentes no Norte Goiano. Nas considerações finais, serão apontadas algumas perspectivas, face às novas dinâmicas sociais, na persistência e construção de identidades. Não temos a pretensão de com este artigo dar todas respostas, e sim de suscitar mais interrogações.

\section{O território de desencontro e de descoberta do Outro}

Território tornou-se um termo bastante banalizado, sendo empregado, às vezes, por pura comodidade de linguagem, com o sentido de "espaço" ou de "região". Haesbaert (2001) entende que esta confusão estabeleceu-se quando alguns geógrafos, antropólogos e sociólogos, entre outros, passaram a considerar qualquer base material sócio-espacial, apropriada, como território ${ }^{2}$.

A despeito de não ser um termo próprio do vocabulário dos geógrafos, em poucos anos, território tornou-se uma das palavras-chaves na Geografia. Três idéias habitualmente são utilizadas pelos geógrafos em seus estudos espaciais: o de área dominada pelo controle territorial, o de limites face às fronteiras e àquela da dominação vinculada ao poder do governante. Para Le Berre (1992) a palavra território quando usada na Geografia revela uma dupla filiação: uma é proveniente diretamente do domínio jurídico, presente na expressão aménagement $d u$ territoire, e a outra é aquela de inspiração mais nova, resultante dos avanços feitos pela Etologia, Antropologia, Psicologia e pela Sociologia disciplinas das quais a Geografia tem se aproximado. Isso nos auxilia a entender, em parte, o porquê dessa polissemia em relação ao vocábulo território.

A imprecisão de sentido de território autoriza o uso de varias acepções do termo, desde a referência ao espaço político limitado pelas fronteiras do poder até uma alusão ao espaço efêmero dos povos errantes, grupos sociais em deslocamento, como os ciganos, os sem-terra e os atingidos pela construção de hidrelétricas e barragens. Face às conjunturas ambientais mais recentemente alguns antropólogos, como Escobar (2000), chegaram a propor uma função ecológica do território, dada a existência particular da biodiversidade e de recursos hídricos, como seria o caso da área do Lago da UHE da Serra da Mesa. Neste 
artigo, quando nos referimos ao território do Lago da UHE Serra da Mesa, estamos levando também em consideração a sua função jurídico-política, técnica, econômica e social, bem como as representações e lógicas culturais que lhe são atribuídas. Isto posto, cabe registrar que é da diversidade dos grupos sociais que resulta àquela dos territórios- a dimensão, as configurações espaciais, as funcionalizações do território. Além disso, muita coisa pode modificar de um território para outro e novas fronteiras podem ser, assim, construídas. Como existe uma dinâmica que anima as fronteiras e os territórios, especificaremos aquela do Lago da Usina Hidrelétrica da Serra da Mesa.

A Usina Hidrelétrica é um projeto que remonta o ano de 1978. Três anos mais tarde, foi outorgada a Furnas Centrais Elétricas S.A a concessão para o desenvolvimento progressivo do potencial hidrelétrico existente no trecho do rio Tocantins e seus afluentes espalhados no Norte Goiano. Em 1986, foi iniciada a construção, tendo uma paralisação no final dos anos oitenta por escassez de recursos financeiros. A retomada da obra foi possível somente no inicio da década de 1990, com o aporte de capital público e do capital privado fornecido pelo Consórcio Serra da Mesa Energia S.A. A UHE de Serra da Mesa foi a primeira hidrelétrica a ser fruto de parceria do Estado com a iniciativa privada. Desse modo, a participação de uma empresa privada assegurou desde esta fase os interesses de grupos de empresas que se beneficiam enormemente com os investimentos do setor elétrico. Ao Consórcio coube concluir as obras recebendo, em contrapartida, 51,54\% da energia produzida por aquela usina. Em 1997, a totalidade das ações da Serra da Mesa S/A foi alienada para a VBC Energia -empresa formada por alguns dos exintegrantes do Consorcio- constituída pelos grupos Votorantin, Bradesco e Camargo Correa, conforme afirma Andrade (2002). Desde então, a VBC Energia é a proprietária daquele empreendimento, cabendo à Furnas o gerenciamento do empreendimento e a responsabilidade pela operação da usina.

A barragem da UHE formou um lago,desde 1998, que ocupou uma área maior que da cidade de São Paulo (1. $784 \mathrm{Km} 2)$.O Lago chega atingir até 70 metros de profundidade e inundou parte dos municípios de Niquelândia, Santa Rita do Novo Destino, Minaçu, Uruaçu, Campinorte, Campinaçu, Colinas do Sul e Barro Alto situados no Norte Goiano. Foi um empreendimento técnico-econômico que levou a refuncionalização daquele território. Além das características geológicas, geomorfológicas e do potencial hidrelétrico, outros fatores históricos e socioeconômicos favoreceram a localização do empreendimento na região e merecem ser também explicitados.

A região do Norte Goiano conheceu uma das mais significativas ocupações indígenas das mais significativas entre todas as províncias brasileiras.Ela perdurou até a chegada de bandeirantes e sertanistas atraídos pela captura de índios e busca do ouro. A mineração propriamente dita, de 1726 a 1750 , favoreceu o interesse em encontrar novos "descobertos" de ouro, fazendo com que toda a Capitania de Goiás fosse percorrida pelas bandeiras. De acordo com Palacín e Morais (1989), arraiais surgiam e populações se fixavam onde encontrassem o ouro. Na extensa área entre o Tocantins e os chapadões dos limites com a Bahia, na grande parte árida e áspera, destacavam-se, naquele período, as povoações de Arraias, São Félix e Cavalcante. Nos idos de 1734, as minas de ouro conferiram a emergente Cavalcante o titulo de capital regional, responsável pela ocupação em toda Chapada dos Veadeiros, posição mantida até meados do século XX.

Neste período, tendo em vista que a riqueza se media pela posse dos metais preciosos, tanto os governantes como o povo definiram que todos os esforços de capital e de mão-de-obra deveriam concentrar-se na produção do ouro. Isto nos explica o pouco desenvolvimento da lavoura e da pecuária e o porquê de não floresceram outras formas importantes de economia durante o século XVIII, e somente fossem ocupadas às áreas auríferas.

Quando se evidenciou o esgotamento da mineração, a população decresceu na Província e coube à 
pecuária, como nova alternativa econômica, restabelecer e aumentar novamente a população. Vale destacar que a agropecuária sempre existiu em Goiás, desde os tempos do ouro. Mesmo como atividade secundária desenvolveu-se no Norte pelos descampados de Arraial de Flores e Arraias. Para Barreira (1997), foi o gado que ligou Goiás a várias regiões do Brasil, evitou a total falência econômica de Goiás e fez a fixação do homem e a ocupação de novas parcelas do território goiano.

O Norte apresenta algumas particularidades paisagísticas e sócio-espaciais que o diferenciam das demais regiões do território goiano. O predomínio das formas serranas, o relevo formado por vales e chapadas, com vales de rios extremamente encaixados e as rupturas de declives favoreceram o aparecimento de inúmeras quedas d'água e cachoeiras. Em direção ao Nordeste Goiano, a existência de relevo cárstico com inúmeras cavernas e grutas, formaram terras que não constituíram um atrativo para a implantação de grandes fazendas destinadas a agropecuária, embora algumas delas tenham obtido sucessos. Prevaleceu, porém, uma área bastante antropizada devido ao cultivo de pastagens e tratos agrícolas, com pastos, capoeirões, entremeados com pequenas e esparsas manchas remanescentes de vegetação natural- matas ciliares, mata de galeria, cerradão-, principalmente nos terrenos de declives e encostas e naqueles de difícil acesso pelas cotas altimétricas mais elevadas.

O modo de vida das populações locais era e permanece ainda essencialmente rurícola. Esse modo de vida é determinado pelo quotidiano e pelas práticas culturais, pelas percepções da natureza e pela condição de morador do sertão com o plantio de milho, feijão, algodão, mandioca e cana-de-açúcar, pequena criação e a produção de farinha, queijos, leite e de rapadura, já comentado por Bertran (1994). Além disso, de 1970 a 1990, a área caracterizava-se pela fragilidade econômica dos pequenos agricultores que procuravam na exploração do ouro algum rendimento. As práticas bastante rudimentares davam, contudo, um retorno mínimo para os agricultores, pois a atividade, há algumas décadas, já denotava declínio. Este território, a despeito da povoação antiga, consolidou uma frágil articulação com o centro e a capital de Goiás, apresentando grande carência de infra-estrutura, baixos Indices de Desenvolvimento Humano-IDH, quando comparados com a média do estado.Para ilustrar esta afirmação, os dados de 2002, do Anuário Estatístico do Estado de Goiás (SEPLAN, 2003) de alguns municípios, no que diz respeito ao numero de ligações da rede de esgoto da SANEAGO apontam: em Minaçu 742 ligações, em Niquelandia 26 e nos municípios de Alto Paraíso de Goiás, Campinaçu, Colinas do Sul, Cavalcante e Uruaçu o fenômeno sequer existe. No que concerne ao IDH há variações entre os municípios: Alto Paraíso de Goiás 0,738, Campinaçu 0,733, Colinas do Sul 0,671, Cavalcante 0,609, Minaçu 0,749, Niquelandia 0,739 e Uruaçu 0,738 . O IDH de Goiás, em igual período, foi 0,776 e os municípios do Norte Goiano aqui representados estão aquém desse índice.

Também, o Norte Goiano não conheceu, de forma efetiva, o processo de inserção na expansão da fronteira agropecuária e sua modernização, parcialmente freada pelos limites estabelecidos pelo Parque Nacional da Chapada dos Veadeiros e o relevo mais movimentado. Dos grupos indígenas que ali dominavam até o século XVIII restaram os Avá-Canoeiro. É bom salientar que após a construção do Lago da UHE da Serra da Mesa, os seis indivíduos sobreviventes desse grupo foram confinados em uma reserva indígena. Não resta dúvida de que a escolha do local para a construção do Lago da UHE Serra da Mesa considerou, também, esses fatores. O processo, as desapropriações e os impactos ambientais, políticos e econômicos decorrentes da construção da Usina Hidrelétrica enfrentariam, neste contexto, poucos conflitos in situ.

Na visão de Andrade (2002), as mudanças já estavam em curso desde a "Marcha para o Oeste" e a Usina Hidrelétrica configura-se de indutora de um processo que era irreversível.Vejamos como nestas mudanças a fronteira materializou-se para as populações sertanejas do Norte Goiano. 
A construção da Usina Hidrelétrica de Serra da Mesa implicou em uma mudança drástica na paisagem local. A Hidrelétrica, na concepção de seus idealizadores, tornou-se o sujeito daquele ambiente,isto é do sistema elétrico. Ao contrário de interferir no meio de vida das populações afetadas, a obra foi considerada pelos idealizadores como sendo afetada por ambiente que incluía essas populações. Isso não foi diferente do fato anteriormente ocorrido com a construção da Hidrelétrica de Xingu. Sobre essa Hidrelétrica e o seu local, os documento oficiais referiam-se "a ocorrência com freqüência de indígenas na área do empreendimento". Com esta percepção, conforme comentário pertinente de Castro e Andrade (1988), distorce-se o fato de obras hidrelétricas estarem "ocorrendo" com freqüência em áreas indígenas.

A represa e a Usina Hidrelétrica, cuja construção levou aproximadamente 15 anos, gradualmente configurou-se uma outra paisagem.Técnicos, barrageiros, maquinários, pesquisadores, veículos pesados e leves, sons de motores, de dinamite, de mando, o pó da poeira com o canteiro de obras e o trânsito intenso, tudo em constantes deslocamentos inseriram-se na paisagem em mudança. Acampamentos espalharam-se pelas imediações da obra ocupando o cerrado e áreas de pastagens. Depois que a represa foi concluída, as águas submergiram as várzeas aluvionais tidas como as melhores terras para agricultura. As tradicionais áreas de garimpo foram inundadas. Os vales, áreas anteriormente ocupadas por cerrado, as cavernas, as estradas, as pontes, os roçados, as fazendas, os engenhos, os currais, os cemitérios, foram substituídos por um imenso espelho d'água. Essa represa é orgulhosamente apresentada nos folhetos de turismo como a "maior do Brasil em volume armazenado".

Desta forma, outras relações e modos de ver o território tiveram de ser estabelecidas com o chegante, o empreendedor, o técnico da Usina Hidrelétrica que induziram novas concepções de vida, sobretudo em relaçao à mudança social. As terras, geralmente de preço inferior aquele de demais regiões goianas, revalorizaram-se e atraíram grileiros. Em busca de terras de localizações privilegiadas, os fazendeiros, principalmente paulistas, compraram áreas de cerrado nas imediações do Parque Nacional da Chapada dos Veadeiros, formando um corredor entre o Parque e o Lago. Outros investidores, vindos principalmente de Brasília e Goiânia, cobiçaram as margens do Lago para construírem residências secundárias, condomínios e empreendimentos turísticos. A fronteira estava materializada nas obras da Usina Hidrelétrica, nas pessoas recém-chegadas, e nas relações sociais novas, posto que mesmo as velhas relações sociais foram modificadas pela alteridade.

A forma de representações da fronteira é desigual entre os diversos segmentos sociais ali presentes; cada representação corresponde a um interesse diferente. Para determinados grupos sociais como as populações tradicionais, o sertanejo, a fronteira constitui uma forma de vida; para outros como o investidor, o pecuarista, ela constitui um recurso real e ou potencial. A fronteira tende a provocar a dicotomia entre as identidades territoriais, pois ou é deste território ou não é. Isso nos leva a entender porque a fronteira é considerada como espaço de conflito(MARTINS, 1997) e porque os discursos sobre a fronteira não são, de modo algum, uníssono. Há fronteiras sociais e culturais de distintos grupos sociais/atores locais, distantes e próximos, que se defrontam no espaço do Lago Serra da Mesa. Conforme Del Rio (1998, p. 465), "as relações que se estabelecem no seio dos diferentes grupos que se interrelacionam em um espaço e tempo determinados são fundamentais para compreender a construção e a desconstrução de fronteiras".

De fato, a fluidez da fronteira permite-nos considerar sua existência no Norte Goiano como momento em que ocorreu a instauração do novo, com a Usina Hidrelétrica e suas implicações sócio-espaciais. Como afirma Bhabha (2003, p.19) "encontramo-nos no momento de trânsito em que espaço e tempo se cruzam para produzir figuras complexas de diferença e de identidade, passado e presente, interior e exterior, inclusão e exclusão".

Antes da construção da UHE Serra da Mesa, as expectativas foram enormes em relação ao projeto em 
si, geradas por boatos contraditórios. Havia, conforme Andrade (2002, p.186), “esperança de criação de empregos e de melhoria econômica incrementada pelas obras e o medo de se perder elementos paisagísticos culturais" relacionados com o seu território identitário Entretanto, as obras têm uma duração efêmera e não foram suficientes para dinamizar a economia local.

De acordo com levantamento feito por Rigonato (2005), em 2004, no povoado de Vila Borba, distante $8 \mathrm{~km}$ do Lago da Serra da Mesa, no universo de doze entrevistados apenas um morador mencionou o emprego como uma das mudanças ocorridas com a UHE. Porém, pelo menos cinco lavradores mudaram de profissão e atualmente são agente de saúde, doméstica, diarista, comerciante e cabeleireiro. Dois antigos pecuaristas hoje trabalham um no comercio e o outro na serralheria e ainda mantém a propriedade rural. Entre os aspectos positivos, a população destacou a facilidade de transporte com a melhoria da estrada que acessa a sede do município- e coincidentemente ligava também a sede ao Lago-, aumento dos turistas praticantes da pesca esportiva e a energia elétrica.

Esses moradores são mais sensíveis a comentarem sobre as suas perdas. Em pesquisa coordenada por Almeida (2005), em Campinaçu, falar sobre o Lago é a ocasião para lamentar o desaparecimento das terras férteis submersas. Em Vila Borba e Minaçu, os moradores relembram como morreu uma parcela significativa de seus rebanhos com uma epidemia de raiva bovina, transmitida pelos morcegos surgidos após a inundação de seu habitat natural. Em Campinorte, logo que o Lago começou a se encher, havia uma expectativa do alcance do nível das águas para 460 metros o que provocou uma corrida para a compra de terras e a construção de casas para as proximidades daquela cota prevista.Todavia, isso não se concretizou gerando frustrações e prejuízos para os investimentos turísticos. Houve, também, perda ecológica com o desaparecimento da anta, do veado, há pouca capivara e há predominância do peixe tucunaré. Em Vila Borba, os moradores apontam como mudanças também o sumiço de animais, o desaparecimento de madeira e de várias espécies consideradas medicinais- boa parte coberta pelo espelho d'água. Por todos estes municípios, o lamento dos moradores diz respeito ao relacionamento social, à falta de pessoas que abandonaram o lugar, às restrições impostas com o Lago, como por exemplo, a proibição de garimpo, às desapropriações que, em alguns casos, nem chegaram a serem pagas e famílias ainda continuam morando de favor em terras alheias.

Neste território de fronteira, nas palavras de Canclini (2000, p.198) as "economias cruzadas, sistemas de significados que se intersectam e personalidades fragmentadas", as ações simbólicas cotidianas são a garantia da continuidade do grupo social que já estava estabelecido no local e servem para delimitar e reproduzir as fronteiras culturais com outros grupos em função do acesso desigual aos símbolos. No território de fronteira, qual é a linha imaginária que define as diferenças culturais?

\section{Identidades e alteridades}

Como organização do espaço, pode-se dizer que o território responde, em sua primeira instância, a necessidades econômicas, sociais e políticas de cada sociedade e, por isso, sua produção está sustentada pelas relações sociais que o atravessam. Sua função, porém, não se reduz a essa dimensão instrumental; ele é também objeto de operações simbólicas e é nele que os atores projetam suas concepções de mundo.

São, assim, vários os níveis de análise e de escalas espaciais que permitem a compreensão do território, fato que nos possibilita cogitar que são tantos territórios quanto são os enfoques feitos sobre eles. O olhar geográfico, portanto, além de ser seletivo quanto aos níveis de análise é também multiescalar mesmo no que diz respeito aos territórios ${ }^{3}$.

O território se pluraliza segundo escalas e níveis historicamente constituídos e sedimentados, englobando escalas como o local, o município, o estado, a região e o país. Estas diferentes escalas não 
constituem um continuum, mas níveis imbricados ou superpostos4. Nesta análise estamos considerando somente os territórios próximos ou identitários (os povoados, as comunidades, o município) a despeito de termos clareza de que a UHE Serra da Mesa vincula esses territórios aos territórios mais vastos seja pela VBC, sua proprietária, seja pelos consumidores de sua energia espalhados pelo Nordeste e Centro-Sul5. A região, denominada Norte Goiano, é a conjunção entre os territórios próximos e distantes, isto é, um mais da vivência e de deslocamentos freqüentes e o outro mais abstrato, portador de uma percepção subjetiva. Conforme já foi dito anteriormente,a região do Norte Goiano, apropriada pela lógica do capital industrial-financeiro, tornou-se o território do Lago da UHE Serra da Mesa.

Como também já dissemos, território ele o é, para aqueles que têm uma identidade territorial com ele, o resultado de uma apropriação simbólico-expressiva do espaço, sendo portador de significados e relações simbólicas. Bonnemaison e Cambrezy (1997; p. 10) consideram que " o vigor do laço territorial revela que o espaço é investido de valores não somente materiais mas também éticos, espirituais, simbólicos e afetivos". A cultura, portanto, inscreve-se assim no território, deixando marcas pela história e pelo trabalho humano o que, no nosso caso, pode ser apreendido pelos diferentes processos de apropriação do Norte Goiano. Cremos que não seria exagero cogitar nesses territórios sítios potenciais de resistências, intervenção e de tradução decorrentes das estratégias de diferenças. Culturalmente, estas estratégias constituem o fundamento para um novo tipo de "localismo," que não é auto-suficientemente particular, mas que surge de dentro do global, sem ser simplesmente um simulacro deste (HALL, 2003).

Nesse estudo propomos discutir sobre os espaço identitários, buscando esclarecimentos sobre o processo atual das persistências e ou reconfigurações identitárias notadamente em uma área de fronteira. Outra proposta foi fornecer elementos de compreensão de como se pratica uma identidade sertaneja, no Norte Goiano, espaço onde a linha que separa a cultura da natureza apenas se esboça, e as sociedades sertanejas tradicionais se formam, se desorganizam e se reproduzem, nas palavras de Martins (1997), mesmo quanto ameaçadas.

Esta discussão cabe bem na ciência geográfica, uma vez que o espaço é tido como o lugar onde se aplica uma estratégia identitária. É o espaço que fornece ao sujeito um campo para suas realizações existenciais, físicas e organizacionais. Investir fisicamente um lugar é, ao mesmo tempo, instituir um território,e na opinião desse mesmo autor "é produzir um significado que substitua a ausência" (idem).

A identidade, segundo o Dicionário Houaiss de Língua Portuguesa,(2001) é o “conjunto de características e circunstâncias que distinguem uma pessoa ou uma coisa e graças às quais é possível individualizá-la". Aqui concebemos identidades as "situações que se diriam culturais na medida em que elas traduzem momentos, atributos, territórios julgados significativos ou característicos de um grupo social sobre espaços e temporalidades determinadas"(VIGNAUX; FALL, 1997, p.303).

Claval (1995, p. 146), a propósito da identidade cultural, sugere considerar três elementos para a sua formação: "a origem comum, o desejo de adequar-se às práticas de um grupo e a construção da pessoa que repousa na articulação exercida de todos os aspectos de sua vida centrados na cultura", ou seja, assumir-se como parte de um grupo com dados valores culturais e praticá-los.

Para Bassand (1999), citado por Giménez (2000), três são os tipos de identidades: a identidade histórica e patrimonial, construída em relação com acontecimentos passados importantes para a coletividade e ou com um patrimônio sociocultural, natural ou socioeconômico; a identidade projectiva, fundada em uma representação mais ou menos elaborada do futuro do território, levando em conta seu passado; a identidade vivida, reflexo da vida cotidiana e do modo de vida atual do território. A identidade pode conter, em forma combinada, elementos históricos, projetados e patrimoniais. Freqüentemente esses três tipos de identidades imbricam-se para definir e constituir uma identidade territorial que, também, pode, 
às vezes, ser assumida isoladamente pelos atores sociais.

Há singularidades na construção da identidade territorial. Com muitas pessoas chegando ao Norte Goiano, por exemplo, a população, local, passou a reivindicar uma identidade diferenciada. Os ambientalistas introduziram o termo nativo, referindo-se a distintos grupos que tradicionalmente viviam naquela região. No início rejeitado, atualmente o auto-reconhecimento como nativo é valorizado pelas populações locais pois ele integra o discurso sobre um tipo de saber que só detém quem é do lugar. A representação que tem as pessoas de sua posição no espaço social e de sua relação com outros agentes que ocupam a mesma posição ou posições diferenciadas no mesmo espaço é fundamental para definir a identidade.

De acordo com o grau de pertencimento ou de identidade dos habitantes de um dado território, Bassand(1999) estabelece a seguinte tipologia:

1) os apáticos e os resignados: destacam-se pela atitude passiva e por não se identificarem com os interesses locais e territoriais;

2) os migrantes potenciais: aqueles que não vêem perspectivas de realizações de seu projeto pessoal naquele território e estão buscando ocasiões para migrarem;

3) os modernizadores: são aqueles adeptos de todas as formas de modernização. Este tipo geralmente forma a parcela dos bem sucedidos na política e na economia local e são quase sempre depreciadores do patrimônio e da história local que consideram como tradições obsoletas e retardatárias.

4)os tradicionalistas: dotados de uma identidade histórica, patrimonial e emblemática muito forte são os que reivindicam um projeto territorial consistente para congelar a região em seu estado de desenvolvimento atual, ou seja, em reconstruí-la segundo um modelo antigo de caráter mítico.

5)os regionalistas: são os que preconizam o desenvolvimento autônomo de sua região a qualquer preço e mediante ao recurso de qualquer meio uma vez que consideram asfixiante o centralismo estatal.

Esses cinco tipos de identidades territoriais têm suas representações no Norte Goiano, assumidas por diferentes grupos sociais e revelam uma dada consciência sócio-espacial. A grosso modo, os apáticos e possíveis migrantes são encontrados entre os pequenos agricultores, antigos garimpeiros e a geração de jovens nativos. Os regionalistas e os modernizadores correspondem aos políticos, comerciantes e empresários de empreendimentos turísticos, enquanto os grupos sociais vinculados às atividades extrativistas $\mathrm{e}$ de uma relação mais íntima com o cerrado incluem-se naquelas dos tradicionalistas. Como já aludimos, no território de fronteiras, para Martins (idem, p. 151), aqui estão configurados "modos de ser e de viver no espaço novo(...) de desencontradas perspectivas”. Espaço, portanto, de contradição e de conflito.

De acordo com Giménez (2000) a identidade é criatividade permanente e exploração contínua, o que implica em uma dialética de continuidade e troca; e esse autor ressalta que na nossa época a identidade já não pode fundar-se exclusivamente no culto as próprias raízes e tradições sob pena de perecer-se por asfixia.

Castells (1999) compartilha da opinião de Gimenez (2000) ao enfatizar a construção da identidade, como um construto histórico para o qual contribuem a História, a Geografia, a Biologia, instituições, a memória coletiva, fantasias pessoais e aparatos de poder e revelações de cunho religioso. Segundo ele, esses materiais são reelaborados pelos indivíduos, pelos grupos sociais "em função de tendências sociais e projetos culturais enraizados em sua estrutura social, bem como em sua visão de tempo/ espaço"(CASTELLS,1999, p.23).

Analisando a condição daqueles que se encontram no território de fronteira e possuíam um enraiza- 
mento territorial nota-se que a identidade adquire feições de resistência , discussão feita pelo Castells, (idem,p.24) e utilizamos face às mudanças provocadas pela construção do Lago da UHE Serra da Mesa, " pelos atores que se encontram em condições desvalorizadas e/ou estigmatizadas pela lógica da dominação, construindo, assim trincheiras de resistência e sobrevivência”. Já fizemos uma alusão a essa resistência e já comentamos sobre a revalorização da condição de ser nativo. Consideramos, também, como uma forma de identidade de resistência a singular negação da inserção do Lago às práticas sociais e culturais locais.O Lago existe para quem é de "fora", que o busca e freqüenta para o seu lazer, permanecendo para a população anteriormente territorializada, a continuidade de formas de lazer associadas às comemorações e festas conforme as estações do ano e atividades de plantio e colheita.

Para Vignaux;Fall(1997), os territórios identitários são espaços e temporalidades necessariamente móveis, não apenas porque estão em evolução, de acordo com a história, mas também porque eles se definem e se legitimam pela fronteira de outros espaços e tempos, também, batizados de culturais.

Conforme discutimos na primeira parte deste texto, procuramos apresentar como a construção do Lago da UHE Serra da Mesa configurou-se como uma fronteira, representando igualmente o limite da territorialidade que tem como suporte a alteridade. A alteridade compreendida não só como o reconhecimento da existência do Outro, o semelhante, mas tudo que é exterior ao Eu. A fronteira é, portanto, principalmente o espaço de alteridade do Eu e do Outro, no qual se observam, se comparam, identificam suas diferenças, criam opiniões sobre si mesmo e sobre o Outro como, conscientemente cada um pode adotar ou não traços do Outro; porém, cada um também pode afirmar sua própria identidade. Procuramos destacar o processo que instaurou o espaço de alteridade desde a concepção do projeto de construção da hidrelétrica e ainda em curso.

Mas a fronteira não é apenas esta dualidade. Segundo Martins( 1997), a fronteira é de muitas e diferentes coisas: fronteira da civilização, fronteira espacial, fronteira de cultura e visões de mundo, fronteira de etnias, fronteira da História e da historicidade do homem. Segundo ele ela é, no âmbito da concepção do homem e do espaço, "ponto limite de territórios que se redefinem continuamente, disputados por diferentes grupos humanos"(MARTINS, 1997, p.11). De fato, no que concerne à diferença cultural os embates de fronteira que afloram tanto podem ser conflituosos como consensuais. Para Bhabha (2003) a fronteira, é também espaço liminar e processo de interação simbólica, o tecido de ligação que constrói a diferença. Corresponderia ela, portanto, a um “entre-lugares". Entre suas importâncias està o fato de que, como passagem, evita as identidades a cada extremidade de se cristalizem em polaridades.

Alguns autores têm procurado superar uma leitura dicotômica ( desconhecido-conhecido, novo-velho) e do entendimento de fronteira apenas enquanto barreira e obstáculo. Del Río (1998), por exemplo, faz referência a uma fronteira política e a uma fronteira cultural. Preocupado em articular as idéias de processo de identificação-fronteira-territórios locais-Estado, ele destaca seu entendimento da fronteira como separação, mas também comunicação devido às suas múltiplas formas. O entendimento de Garcia (2002) situa a fronteira como um conceito positivo que remete à uma síntese de conexão, vínculo e interdependência das sociedades. Já Hall (2003) admite os binarismos, porém, ressalta a função da fronteira, sobretudo, como place de passage, respaldando-se em Bhabha.

Na opinião de Bonnemaison; Cambrezy (1996) a fronteira em si não é restritiva, limitante, nem deve ser vista como um instrumento de fechamento sobre orientações identitárias particularistas.Com efeito, a existência de fronteiras não significa somente uma divisão espacial de território e elas exprimem uma certa relação ao território, uma outra visão de mundo, da moral e do direito.

$\mathrm{Na}$ leitura da fronteira aqui abordada, há um território identitário. Procuramos adotar o ponto de vista de Martins “ fronteira de cultura e de visões de mundo", o de Bhabha considerando a fronteira o tecido 
de ligação que constrói a diferença, e concordando com Bonnemaison; Cambrezy em interpretá-la como uma certa forma de estar no território.

De acordo com Fay (1996, p.43), a cada momento todo território é ou foi bem um território identitário, pois "este é um jogo de identidades relacionais (homens/elementos-divindades poderes, que estabelecem suas fronteiras fundadoras". As mudanças de fronteiras vão juntas com as reidentificações, as ressignificações e as recomposições territoriais. Relembrando as discussões de Claval (1995, p.148), os sentimentos de identidade criam territorialidades porém, "o cuidado de preservar sua identidade não impedem a esses grupos sociais de ter relações com aqueles que são diferentes, adotando, todavia, limites protetores que os impeçam de aceitar o que ameaça seus valores essenciais".

\section{Considerações finais}

A identidade, nos lembra Haesbaert (2001), depende profundamente dos constructos referentes a determinados recortes geográficos, tenham eles um caráter mais concreto ou mais abstrato. Todo esse universo, pela sua dinâmica histórica e política, nos revela o território, resultado da valorização e da apropriação do espaço, contendo uma valorização simbólica, identitário-existencial. Esse território é visto como local de confronto das manifestações dos grupos sociais, neste caso em discussão das populações tradicionais do Cerrado do Norte Goiano, na recomposição contínua de seus espaços de interações, segundo suas necessidades e desejos e, das formas objetivadas e programadas de uso e gestão do Cerrado.

Os territórios identitários, pela análise feita, são envolvidos numa relação de alteridade com a fronteira configurada na construção do Lago da UHE Serra da Mesa. Conforme a tipologia proposta por Bassand, moradores tradicionalistas, em sua maioria, hoje se confrontam com os modernizadores. Esse confronto configuraria como a fronteira, também já discutida, entre o "Eu" e o "Outro", enfatizando que se existe "Eu" é porque este pode diferenciar-se do "Outro". Isso constitui o limiar tênue entre os interesses distintos tendo em vista um Norte Goiano percebido, primeiramente pelo capital industrialfinanceiro do Sudeste-Sul do país interessado na produção de energia para seu consumo, e, atualmente, pelos investidores empresários do turismo e da soja e do sorgo assunto não abordado aqui. Para os grupos sociais de populações tradicionais,o território constitui um significante e um significado, pois este seria, segundo Giménez (2000), fonte de vida e de recursos, objeto de apego afetivo, espaço em que o passado e a historia imprimiram suas marcas, uma paisagem mas, também, uma área geopoliticamente estratégica por constituir-se um recorte político-administrativo.

Face às investidas exteriores, à condição de território de fronteira, mutações estão em curso nos territórios identitários. Insistimos aqui, pois, em uma afirmação anterior ( ALMEIDA, 2003). Há uma persistência de identidades sócioterritoriais em formas modificadas e segundo configurações novas. Assim, por exemplo, o território perdeu seu caráter totalizador, deixando de ser um horizonte de orientação unívoca para a vida cotidiana das pessoas e grupos. Hoje tais grupos preocupam-se com as relações que se fortalecem com os territórios distantes: estas consolidam-se devido à busca de núcleos urbanos para a educação dos filhos,à procura do dentista, à ida ao médico ou a à agência bancaria para receberem as aposentadorias, à chegada crescente e ansiada dos turistas vindos até mesmo do exterior e à passagem dos esporádicos compradores de garrafadas... Assim, borram e embaçam as fronteiras. Também, o próprio pertencimento sócioterritorial tende a fragmentar-se, tornando-se multifocal. Para muitos indivíduos o pertencimento esgarça-se por uma prolongada ausência dos seus lugares, por razões diversas e, para outros,por exemplo, pelos processos desterritorializantes, na relação com grupos de outros territórios. Modelam-se, pois, territórios culturalmente mais híbridos graças às construções de novas identidades. 


\section{Notas}

(1) Este artigo resulta da pesquisa "Cultura, conhecimento popular e o uso das espécies naturais por parte dos pequenos produtores do Cerrado"- 2000-2002 (apoio CNPq) e da pesquisa "As potencialidades turísticas nos municípios do entorno do Lago da UHE da Serra da Mesa" ( apoio SECTEC-GO,2002-2005). O mesmo foi apresentado na Mesa Redonda Território e Identidade do IV Simpósio Nacional sobre Espaço e Cultura, 27/10/2004, promovido pelo NEPEC-UERJ

(2) Benko \& Pecqueur (2001) chegam mesmo afirmar “As regiões, ou ainda melhor, os territórios..." (p. 40).

(3) As discussões sobre território têm resultado em uma produção significativa. A título de exemplo citamos Santos, M. (1996; 1999), Souza, M. L. (1995; 2001), Haesbaert, R. (1997; 2001; 2002, 2004) e justificamos nossa opção em não aprofundar aqui este tema.

(4) Em texto anterior (2004) referimo-nos à teoria dos "territórios empilhados" proposta por Yves Lacoste (1993) para explicar a relação hierárquica existente entre o local e o município, entre este e o estado e assim sucessivamente, (5) De acordo com FURNAS gerando 1.275 MW de energia,a UHE Serra da Mesa tornou-se indispensável ao atendimento do mercado de energia elétrica do Sistema Interligado Sul,Sudeste-Centro-Oeste e é o elo da Interligação Norte-Sul.

\section{Referências}

ALMEIDA, M.G. A Reinvenção da Natureza. Espaço e Cultura. Jan-Dez, N. 17 e 18, 2004, p.41-54.

Cultura Ecológica e Biodiversidade. MERCATOR. Ano 2, numero 3, 2003, p.71-82

ALMEIDA, M.G.; VARGAS, M.A.V. A dimensão cultural do sertão sergipano. In: DINIZ,J.A.F.; FRANÇA,V.L.(Orgs.).Capítulos da Geografia Nordestina. Aracaju: NPGEO/UFS, 1998 p. 469-487.

ANDRADE, S. M. O patrimônio histórico arqueológico de Serra da Mesa: a construção de uma nova paisagem. Tese de Doutorado. Departamento de Geografia. USP. 2002.

BHABHA, H. O local da Cultura. Belo Horizonte: UFMG, 1998.

BARREIRA, C.C.M.A. Região da Estrada do Boi: usos e abusos da natureza. Goiânia: Editora da UFG,1997.

BONNEMAISON, J. CAMBREZY. La Lien entre frontierès et identités. Géographie et Cultures, n.20, 1996, pp. 6-15.

CANCLINI, N. G. Escenas sin território:cultura de los migrantes e identidades em transición. In: ARCE, J.M.V.. Decadência y auge de las identidades.Cultura Nacional, identidade cultural y modrnización. Tijuana: El Colegio de la Frontera Norte, 2000, p.191-208.

Culturas Híbridas - estratégias para entrar y salir de la Modernidad. México: Grijalbo,1989.

CASTELlS, M. O poder da identidade. São Paulo: Paz e Terra, 1999.

CLAVAL, P. O papel da nova geografia cultural na compreensão da ação humana. In.. ROSENDAHL Z. CORREAA R.L. (Orgs.). Matrizes da Geografia Cultural. Rio de Janeiro: Ed. UERJ, 2001.

La géographie culturelle. Paris: Nathan, 1995.

DEL RIO, J.M. V. Fronteras,Territorios e identificaciones colectivas. Sevilla:Fundación Blas Infante, 1998.

DIEGUES, A . C. S. Populações tradicionais em unidades de conservação: o mito moderno da natureza intocada. São Paulo: Cebimar/Nupaub, 1993.

DI MÉO, G. Géographie sociale et territoires. Paris: Nathan, 2001. 
ESCOBAR, A.- El final del salvaje. Naturaleza, cultura y política en la antropologia contemporánea. Bogotá: Instituto Colombiano de Antropologia/CEREC, 1999.

FAY, C. Goupes et territoires au Maasina (Mali). Logiques du contrat et logiques de la force. Géographie et Cultures n.20, 1996, pp. 31-44.

HAESBAERT, R. O Mito da Desterritorialização. Rio de Janeiro: Bertrand Brasil, 2004.

Território, Cultura e Des-Territorialização.In: ROSENDAHL, Z. CORRÊA R. L.(orgs.) Religião, Identidade e Território. Rio de Janeiro, EdUERJ, 2001, pp.115-144.

HALL, S. Da diáspora. Identidades e Mediações Culturais. Belo Horizonte: Editora UFMG; Brasília: Representação da UNESCO no Brasil, 2003.

HOUAISS, A. et ali. Dicionário Houaiss da Língua Portuguesa.Rio de Janeiro: Objectiva, 2001.

GARCIA, A . S. Epistemologia del concepto frontera en el pensamiento latino americano. In:ZEA, L. TABOADA, H.(comp.). Latinoamérica en la globalización y el tercer milenio. México: Instituto Panamericano de Geografia e Historia: Fondo de Cultura Econômica, 2002.

GIMÉNEZ, G. Território, cultura e identidades. La región sociocultural. In: BARBERO, J.M.;ROCHE,F.L.;ROBLEDO,A. (eds) Cultura y Región- Bogotá: Ces/ Universidad Nacional /Ministerio de Cultura, 2000, pp. 87-132.

LACOSTE,Y. Préambule/Etat-Nation/Pétrole: Dictionnaire de géopolitique. Paris: Flammarion, 1993.

LE BERRE, M. Territoires. In: BAILLY, A. FERRAS, R. PUMAIN, D.(dir). Encyclopédie de Géographie. Paris: Economica, 199, pp. 617- 638

MARTINS, J.S. A fronteira. A degradação do Outro nos confins do humano. São Paulo: HUCITEC, 1997.

PALACÍN, L.; MORAES, M. A. História de Goiás (1722-1972). Goiânia: Ed. da UCG, 1989.

RIGONATO, V. O modo de vida das populações tradicionais e a inter-relação com a paisagem do Cerrado da microrregião da Chapada dos Veadeiros. Dissertação de Mestrado (Geografia), IESA, UFG, 2005.

VIGNAUX, G. FALL, K. Processus cognitifs, processus culturels, du language et de la culture comme jeux sur "les frontières". In TURGEON, L. LÉTOURNEAU, J. FALL, K. Les espaces de I identité. Québec: Les Presses de I'Université Laval, 1997, pp. 302-313.

Recebido em maio de 2005 Aceito em agosto de 2005 